DOCUMENTO

\title{
Entrevista com Boaventura de Sousa Santos para ANPEd/Brasil
}

\author{
Boaventura de Sousa Santos' D \\ João Marcos Veiga de Oliveira" (D) \\ Maria Luiza Süssekind"II (D)
}

\section{APRESENTAÇÃO}

Conferencista convidado para a abertura da 39a Reunião Nacional da Associação Nacional de Pós-Graduação e Pesquisa em Educação (ANPEd), Boaventura de Sousa Santos, português, nascido em 15 de novembro de 1940, é professor catedrático da Faculdade de Economia da Universidade de Coimbra, Distinguished Legal Scholar da Faculdade de Direito da Universidade de Wisconsin-Madison e Global Legal Scholar da Universidade de Warwick.É também diretor do Centro de Estudos Sociais e coordenador científico do Observatório Permanente da Justiça Portuguesa - ambos da Universidade de Coimbra. Boaventura concedeu longa entrevista ao jornalista da ANPEd João Marcos Veiga sobre o contexto que vivemos de ataques à democracia, educação e pesquisa, sublinhando o tema de sua conferência e a importância de nosso encontro enquanto espaço de conhecimento livre e resistência criativa.

Tendo sido um dos principais impulsionadores do Fórum Social Mundial e fundador da Universidade Popular dos Movimentos Sociais (UPMS) - proposta que contará com assinatura de convênio e sessão pública na reunião da ANPEd -, Boaventura hoje concentra seus estudos na globalização contra-hegemônica e na luta pela justiça cognitiva global, que subjaz ao seu conceito de epistemologias do Sul. No Projeto ALICE, Espelhos Estranhos, Lições Imprevistas, pretende dar continuidade à reinvenção da emancipação social repensando e renovando o conhecimento científico-social à luz das epistemologias do Sul com o objetivo de desenvolver novos paradigmas teóricos e políticos de transformação social. Também poeta e rapper, o bem-humorado e gentil professor tem longa trajetória de pesquisas e lutas no Brasil. Por isso, ciente da gravidade da situação e da urgência de pensar e agir, defender a democracia e a educação e, sobretudo, "enfrentar a injustiça histórica do colonialismo, que hoje continua sob a forma de racismo, de discriminação racial, que tem excluído os jovens negros de uma educação de qualidade, sobretudo universitária", compartilha seus pensamentos conosco nesta entrevista.

Maria Luiza Süssekind

'Universidade de Coimbra, Coimbra, Portugal.

"Associação Nacional de Pós-Graduação e Pesquisa em Educação, Rio de Janeiro, RJ, Brasil.

"'Universidade Federal do Estado do Rio de Janeiro, Rio de Janeiro, RJ, Brasil. 


\section{ENTREVISTA COM BOAVENTURA DE SOUSA SANTOS PARA ANPED/BRASIL ${ }^{1}$}

\section{Qual é a importância da defesa da educação pública e da pesquisa no contexto atual do Brasil, país com o qual mantém proximidade há décadas?}

É máxima a importância nesse momento. Penso que os ataques que estão a ser deferidos contra a educação pública no Brasil, com os cortes a todos os níveis de educação e também à pesquisa, a toda a comunidade científica brasileira, são extraordinariamente negativos para o futuro do Brasil, porque está hoje demonstrado em todo o mundo que em educação pública não há gasto, é investimento no futuro. Também o mesmo se pode dizer da pesquisa, acima de tudo quando os países atingem um patamar em que podem efetivamente competir no âmbito internacional. O Brasil, no domínio da pesquisa, é hoje um país com uma vitalidade extraordinária em todas as áreas científicas, um dos grandes produtores de ciência, em todos os níveis, e naturalmente de uma ciência que pode transformar-se também em tecnologia e, portanto, na valorização da economia, da sociedade em geral. Os cortes são fatais nesse momento, quando os cortes e ataques à pesquisa desmoralizam uma comunidade científica que ainda não foi plenamente consolidada — os investimentos no Brasil ainda estão num nível inferior daquilo que seria necessário para manter o atual ritmo de crescimento que se pretendia e dadas as ambições internacionais com os quais o país regulava até 2014 ou até 2016. O mesmo se pode dizer da educação. A educação em todos os níveis, e particularmente no ensino superior, é aquela que sustenta, em grande medida, a própria vitalidade da ciência, não só porque a esmagadora maioria da pesquisa é feita em universidades, como também porque a ciência é feita pelos cientistas, que têm de ser educados em boas escolas, em boas universidades. Universidades que deem incentivo à sua formação e a seu interesse pela pesquisa. Portanto, no momento em que a educação é vítima de cortes brutais, cegos e indiscriminados, é evidente que isso se repercute de maneira muito negativa em todo o patrimônio científico e educacional do país.

Essas medidas não são novidade. Isto é, toda a lógica do neoliberalismo é uma lógica contra a educação e muitas vezes também contra a ciência, mas não é uniforme em todos os países. O neoliberalismo não quer necessariamente cortar a pesquisa, mas quer direcioná-la de maneira autoritária para as aplicações tecnológicas, industriais e de serviços. Logo, retira da ciência sua capacidade de se aprofundar ao nível da ciência fundamental não aplicada - uma visão estúpida e de curto alcance que o neoliberalismo tem da pesquisa. $\mathrm{O}$ neoliberalismo tende também internacionalmente a ser hostil às ciências sociais e humanas, na medida em que tal pesquisa não dá essa aplicação tecnológica direta com que ele está de alguma maneira obcecado. Mas há também outra razão para essa hostilidade: nas universidades públicas e nessas áreas se produz conhecimento livre, crítico e independente. Isso é fatal para o tipo de modelo político e econômico que o neoliberalismo tenta impulsionar, porque esse modelo é autoritário, dominado pelo capital financeiro global, que convive muito

1 Realizada no dia 27 de maio de 2019, pelo jornalista João Marcos Veiga. 
mal com a própria democracia e que por isso quer se apresentar sempre como um modelo que não tem alternativa. Quando não há alternativa, não há política. Assim, o neoliberalismo é, de fato, uma máquina de antipolítica. Essa antipolítica convive muito mal com o crescimento das ciências sociais e humanas precisamente e tendo em vista que elas produzem conhecimento livre, crítico e independente. Qualquer desses níveis de conhecimento pode questionar o autoritarismo, quer econômico, quer político, que está implícito no modelo neoliberal global.

A nível mundial, é um cenário de um ciclo reacionário em que a gente se encontra, na própria Europa, na Índia, na Rússia, nos Estados Unidos, em muitos outros países, e no Brasil e na América Latina. É um ciclo que se sucede a um ciclo que foi progressista. $\mathrm{Na}$ Europa se designou como social democracia e procurou que a produtividade da economia se repercutisse nos salários. Portanto, deu vazão à criação de amplas classes médias, que caracterizam basicamente hoje o modelo político e econômico da Europa. Mas esse modelo está em crise à medida que tem sido atacado pelo neoliberalismo porque esse modelo, digamos, de distribuição de riqueza não agrada de maneira nenhuma ao capital financeiro global, que é absolutamente voraz no que diz respeito à sua rentabilidade, e isso particularmente no Brasil. Nos outros países, por exemplo, fora da Europa, não houve propriamente uma social democracia consolidada, porém houve entre 2000 e 2013 políticas de redistribuição social bastante importantes e que não se limitaram apenas a essas políticas redistributivas - no Brasil, tiraram da miséria absoluta cerca de $50 \mathrm{mi}^{-}$ lhões de pessoas. Elas também se refletiram nas políticas públicas em geral e nas de educação. Esse foi o período, por exemplo, em que mais floresceu a criação de universidades federais e, por conseguinte, aumentou extraordinariamente a população universitária por meio de ações afirmativas, que procuraram também com isso enfrentar a injustiça histórica do colonialismo, que hoje continua sob a forma de racismo, de discriminação racial, que tem excluído os jovens negros de uma educação de qualidade, sobretudo universitária.

Foi um período de políticas de inclusão social relativamente limitadas, porque o modelo econômico foi o neoliberal, que em certa conjuntura permitiu que todos ganhassem, não apenas os pobres, mas também os ricos - e ganharam muito. Historicamente isso foi em razão do chamado boom das commodities, isto é, do alto preço das matérias-primas e agrícolas, em que o Brasil, por exemplo, foi bastante forte, do mesmo modo a Argentina, permitindo criar excedentes econômicos que se traduziram em políticas redistributivas sem alterar, no entanto, o padrão de injustiça social desses países. Ou seja, a diferença entre ricos e pobres continuou, possivelmente até se aprofundou, mas os pobres puderam ter uma migalha, digamos assim, dessa bonança do boom das commodities e, portanto, melhoraram consideravelmente as suas vidas, entraram no consumo e animaram o consumo interno do país, o que foi absolutamente notável, e os seus filhos começaram a chegar à universidade.

É contra tudo isso que age nesse momento o neoliberalismo na versão brasileira, que é um modelo quase de laboratório. Ou seja, não se trata de um modelo que segue as regras internacionais do que nós temos visto a outros níveis noutros países, como na India, por exemplo, onde o presidente acaba de ter uma retumbante vitória, mas com uma política nacionalista, uma política de criar a ideia da ascensão 
da classe média. No Brasil, ao contrário, temos uma política de destruição das classes médias, que já eram muito minguadas, muito pequenas, num país onde as políticas sociais, sobretudo na educação e nas ciências, não tiveram tempo de se consolidar.

Um investimento na educação, e de maneira especial na educação superior, é um investimento de várias gerações, que só se nota várias gerações depois. Porque é preciso que os formados entrem na vida ativa e profissional, preencham mais lugares no próprio sistema científico, se internacionalizem. E tudo isso leva tempo. Logo, o processo de criação ascendente de um sistema científico no Brasil e de um sistema de educação, mormente de educação superior, mais ampliado, está a ser liquidado, amputado, mutilado. Portanto, está impedindo que possa seguir o caminho de crescimento que tinha. Esses cortes têm um efeito destrutivo notável, porque eles não se refletem apenas no imediato. Refletem-se na desmoralização da ciência e dos cientistas, na desmoralização dos professores e dos estudantes, nos novos gargalos e nos novos impedimentos que vão ser criados às novas gerações de entrarem na universidade e eventualmente depois no sistema científico. Portanto, tudo isso vai repercutir de uma maneira muito negativa nos próximos anos e nas próximas gerações. Por isso me parece que a terapia de choque que está sendo realizada no Brasil, tanto a nível econômico quanto a nível político, é quase uma terapia laboratorial. Nesse momento o Brasil é quase um laboratório de políticas neoliberais extremistas, digamos assim, que vão levar à própria destruição do modelo democrático. $\mathrm{O}$ capital financeiro convive muito mal com a democracia, em todos os países, daí o autoritarismo e o crescimento da extrema direita em vários dele, e nomeadamente na própria Europa, como se acaba de ver nas últimas eleições europeias, embora o crescimento da extrema direita na Europa não tenha sido tão grande quanto ela previa. Assim, essa extrema direita continua ainda a ter de esperar por um novo ciclo eleitoral, para consolidar a sua força e para aumentar, se é que os democratas europeus vão permitir. Mas esse crescimento do autoritarismo está no Brasil a atingir um nível de quase ingovernabilidade, porque é um governo que tem mostrado dificuldade enorme em conviver com as instituições democráticas, seja o congresso, sejam os próprios tribunais - que aliás o levou ao poder, por meio de uma altíssima e grosseira politização da justiça, na Operação Lava Jato, conduzida pelo atual ministro da Justiça e certamente futuro candidato à presidência da república, Sérgio Moro. Portanto, é um nível de ingovernabilidade que normalmente o neoliberalismo evita. É por isso que alguns movimentos conservadores que tiveram papel fundamental no impeachment da presidenta Dilma, como por exemplo o Movimento Brasil Livre, não participaram de manifestações recentes de apoio ao governo.

Eu penso que estamos a atingir no Brasil um ponto particularmente difícil e de bifurcação, como dizemos em teoria da física. Isto é, a partir de agora qualquer novo movimento pode levar a uma grande turbulência na sociedade brasileira. O sistema democrático no Brasil está num período de grande instabilidade, tem uma economia em crise crescente, e a recessão está próxima. É evidente que esse modelo, esse sistema, está desequilibrado. Quaisquer medidas de polarização podem levar a consequências que podem ir para o lado positivo ou negativo, mas que de todo modo vão criar uma crise de institucionalidade. Ora, qualquer que seja o resultado 
dessa crise de curto prazo, ela põe em causa a estabilidade necessária do sistema científico e do sistema educacional que estava a ser construído no Brasil. Portanto, estamos num momento de grande incerteza, a nível político, a nível econômico, que se repercute diretamente no sistema científico e no sistema educacional brasileiro e, nomeadamente, em termos de educação superior.

\section{Professor, o senhor já se referiu a um processo de apagamento da memória que estaria ocorrendo no Brasil, em parte semelhante a fenômenos neoliberais vivenciados no mundo, mas o que o senhor percebe mais especificamente no Brasil sobre esse apagamento dos processos sociais, políticos e de sua história recente no país?}

Como eu digo, o Brasil é um laboratório nesse momento de políticas autoritárias a nível mundial - e elas excedem em muito as fronteiras do país. O Brasil foi alvo de uma ação imperial dos Estados Unidos para tentar neutralizar uma potência de desenvolvimento intermédio e com grande população que poderia de alguma maneira participar de uma alternativa ao capital internacional liderado pelo país norte-americano. Refiro-me concretamente ao papel que o Brasil vinha a desenvolver com a política dos BRICs, com a sua articulação ativa com outros países de desenvolvimento intermédio, que procuravam, fundamentalmente para se protegerem do futuro, criar uma alternativa não socialista, mas uma alternativa capitalista ao capitalismo de influência norte-americana, hoje liderado pelo capital financeiro global e em decadência. É um sistema extremamente instável, porque hoje basta ler o The Wall Street Journal para estarmos conscientes de que se prepara outra crise financeira de grande alcance. Portanto, o Brasil teve de ser neutralizado não só no seu papel internacional de criar uma política internacional relativamente autônoma, que era uma tradição desse período democrático desde 1985, como também numa política econômica relativamente soberana, isto é, não no velho sentido elitista, contudo numa tentativa de colocar a riqueza do país ao serviço do desenvolvimento de todo o país em seu conjunto. Basta ver a questão do pré-sal com a entrega ao mercado internacional dessas grandíssimas reservas de petróleo que existem no Brasil. Tudo isso incomodava muito o imperialismo norte-americano, e o Brasil teve de ser neutralizado, utilizando todos os instrumentos legais e ilegais que podemos imaginar. Para a neutralização ser eficaz, é necessário apagar a memória do que foi feito no período mais recente do país para tornar o Brasil uma sociedade um pouquinho mais justa e mais democrática. $\mathrm{O}$ apagamento deu-se em vários níveis. $\mathrm{O}$ primeiro nível não foi criado por esse sistema atual, que nesse momento está em vigor desde a eleição do presidente Bolsonaro, mas precedeu-o. Foi de fato próprio da natureza da transição democrática no Brasil, que foi uma transição pactuada com as forças armadas, que tinham dominado a ditadura militar no período anterior. Isso impediu que se fizesse uma investigação do terrorismo de Estado que ocorreu nesse período e que, portanto, os autores desses crimes, muitos deles militares de patentes superior, pudessem ir para a prisão - isso aconteceu na Argentina, mas não no Brasil. Logo, houve de imediato um grande esquecimento de todo o passado recente ditatorial do Brasil, precisamente pela natureza do pacto de transição. Isso teve um preço, que foi manter as forças armadas enquanto forças 
de segurança interna, e não apenas de defesa do Brasil contra agressores externos. Elas mantiveram-se ao longo desse período e têm agora grande preponderância no atual governo Bolsonaro. Assim, essa é a primeira dimensão, que não foi criada agora, apenas estavam criadas as condições, por conta da natureza da transição, para que agora fosse praticamente muito fácil trazer oito ou mais generais para postos preponderantes do governo e um vice-presidente. Mais do que isso, as forças armadas são hoje uma força de grande credibilidade democrática no Brasil, apesar de terem sido os grandes arquitetos da liquidação da democracia no Brasil em 1964. Alguns desses militares continuaram, aliás, com posições de mando no período posterior, sobretudo no serviço secreto brasileiro até muito pouco tempo. Portanto, essa é uma primeira dimensão.

A segunda dimensão é que o Brasil teve uma transformação notável com a eleição do presidente Lula, num país onde as elites são patrimonialistas, são herdeiras de toda a desigualdade do período colonial e do período que se prosseguiu, que nós podemos designar como períodos de colonialismo interno. Por exemplo, o Sul com relação ao Norte e ao Nordeste. Portanto, esse modelo sofreu um abalo extraordinário, não no modelo econômico, mas nas lideranças políticas. Continua sendo um modelo econômico que vinha de trás, mas houve uma alteração política, que foi a ampliação das elites políticas, na medida em que se permitiu que um operário metalúrgico chegasse ao poder e o Partido dos Trabalhadores (PT) pudesse se transformar num partido de grande popularidade, de grande poder político, e o seu presidente, ao fim de dois mandatos, saísse do poder com uma taxa de aprovação nunca vista no Brasil e muito raramente noutros países, cerca de $85 \%$ de aprovação. Isso naturalmente teve consequências. Abalou as elites. Elas não deixaram de ganhar, como eu disse há pouco, porque o modelo econômico não foi alterado, mas passaram a se sentir ameaçadas pela maior presença nos corredores do poder de gente que não pertencia a essas elites.

Foi aí que decidiram reagir de maneira brutal com o impeachment da presidente Dilma, como digo, apoiado pelo imperialismo norte-americano, nitidamente articulado com ele. Toda a Operação Lava Jato é uma operação internacional cujos dados fundamentais vêm do Departamento de Justiça dos Estados Unidos e a articulação é feita por meio do juiz Sérgio Moro.

A situação econômica já não era a dos primeiros dez anos, porque o boom das commodities estava a terminar - a presidente Dilma, aliás, começou ela própria a impor alguma política de austeridade. Então, desenhavam-se uma crise e uma elite brasileira pouco habituada a servir a democracia. Está provado hoje que a direita brasileira se serve da democracia, mas não serve a democracia. É por isso que entrou ativamente, quase unanimemente, na política do impeachment da presidente Dilma, que talvez seja a presidente mais honesta da América Latina, impedida pelos políticos mais corruptos da América Latina. Foi uma impaciência histórica da direita e das elites, pouco habituadas à democracia. Porque, como tenho dito muitas vezes, se não tivesse havido o impeachment da presidente Dilma, era bem possível e bem provável que a direita ganhasse as eleições em 2018 tranquilamente. Havia um desgaste muito grande, as condições de governabilidade já não estavam muito bem, porque o boom das commodities tinha terminado, o próprio PT era refém das 
alianças que teve de fazer com o capital brasileiro, e nomeadamente com o capital financeiro, e dificilmente aguentaria manter a popularidade que tinha mantido na década anterior. A direita brasileira, impaciente, achou que era preciso um tratamento de choque e teve o apoio dos Estados Unidos, porque ela sozinha não poderia fazer, ou talvez não fosse a um extremo de fazer uma rendição tão grande, como, por exemplo, a entrega dos recursos naturais, de petróleo, de minério e da Amazônia às grandes empresas multinacionais sediadas nos Estados Unidos.

Portanto, essa elite embarcou. Para embarcar nessa política, teve de apagar da memória todo o momento anterior e criar, com grande apoio dos meios de comunicação, da mídia oligopólica, nomeadamente a Rede Globo e seu grupo, a ideia de que aquela primeira década de 2000 , que o povo tinha saudado ao despedir-se do presidente Lula com taxa de aprovação de $86 \%$, afinal não tinha sido uma época boa, tinha sido uma época de corrupção. Corrupção e nada mais. Isso levou ao apagamento da memória e de todas as políticas sociais que ocorreram nesse período. Esse apagamento de todas as políticas extraordinárias de promoção de educação e de inclusão social por meio da educação, nomeadamente a educação superior, de alguma maneira favorece os atuais cortes de educação. Portanto, desmoralizou essa política social e tornou-a vulnerável a qualquer intenção populista do neoliberalismo, que, como digo, em geral não gosta da educação pública, não só porque ela produz conhecimento livre, crítico e independente, mas porque só olha para a educação como um possível investimento para o capital. Assim, o que quer é privatizar as universidades, privatizar a educação. A educação pública no Brasil estava a ganhar aliados que não eram a classe alta, que deixou há muito tempo de apoiar a universidade pública brasileira, porque mandam os seus filhos para as universidades globais, dos Estados Unidos e da Europa - por vezes até no ensino secundário, no ensino médio. Não confiam no sistema educativo público. Portanto, já estavam a dar menos apoio à educação. Mas o sistema educativo dessa última década estava a conquistar novos adeptos. As classes médias estavam a melhorar seu nível de vida por intermédio do acesso à universidade. Portanto, foi preciso apagar da memória toda essa melhoria para que agora fosse mais fácil criar uma ideologia antieducação, como vimos em manifestações recentes no Brasil, com muitos cartazes contra a própria educação. Então, a educação tornou-se também uma arma ideológica, e a educação pública tornou-se um grande alvo.

\section{O senhor falou de certa incompatibilidade da pesquisa em ciências sociais} e humanas com o próprio neoliberalismo. Qual éo papel da pesquisa nas ciências sociais e humanas e por que há incompreensão por certos segmentos da sociedade e uma deliberada hostilidade por parte do governo atual?

As ciências sociais são um grande instrumento, não necessariamente incondicional, mas são um grande instrumento dos processos de democratização das sociedades. Isso não quer dizer que os cientistas sociais sejam agentes de esquerda necessariamente, mas o conhecimento que as ciências sociais criam permite que se construam argumentos racionais, que se possa argumentar com fatos, e esse conhecimento da sociedade ajuda a mostrar o que nela está errado e deve mudar. O que acontece nesse momento é que nós não estamos no Brasil num momento 
de argumentos racionais. Caímos num momento de argumentos de fé, de crença num líder, de crença nas próprias fake newws, sem nenhuma distância racional. O crivo que está aqui é este: as ciências sociais e humanas são perigosas para o neoliberalismo a vários níveis. O primeiro nível, naturalmente, é que elas permitem criar conhecimento que pode pôr em causa algumas das premissas que o neoliberalismo quer impor autoritariamente. Nomeadamente a premissa de que não há nenhuma alternativa à privatização, à liberalização da economia, à privatização dos recursos naturais, à internacionalização de tudo em quaisquer condições.

Portanto, as ciências sociais e humanas hoje têm argumentos produzidos por cientistas sociais e por economistas no Brasil de grande renome internacional que mostram cada vez mais aquilo que está sendo demonstrado a nível mundial. E que o neoliberalismo não é bom para a economia. O neoliberalismo é uma mentira. O neoliberalismo é um grande sistema que permite transferir riqueza dos pobres para os ricos e das classes médias para as classes altas. Não é bom para criar emprego, não é bom para criar crescimento econômico. A demonstração está feita aliás num pequeno país da Europa, e agora em outros países que estão a seguir a mesma linha, que é Portugal. Portugal entre 2011 e 2015 foi sujeito a uma receita neoliberal bastante dura, não tão dura quanto a que o Brasil está nesse momento a ser sujeito, mas uma receita neoliberal. Desde 2016, o país tem mostrado que, moderadamente, sem radicalismos, é possível criar alternativas às chamadas políticas de austeridade, como são aqui designadas. Apesar disso e por causa disso, o país está a crescer economicamente. Baixou o desemprego, aumentou a paz social, há greves, mas greves são organizadas, têm porta-vozes e têm demandas. Numa democracia é bom que isso exista. Mas a verdade é que a receita neoliberal provou que de fato era um convite ao desastre para esse país. Nesse momento na Europa está a enfraquecer lentamente nesse sentido. A própria Espanha acaba de dar uma vitória retumbante a um partido socialista e já é uma das grandes economias da União Europeia. Logo, mostra-se que de fato não se faz crescer a economia deprimindo salários, deprimindo as pensões, deprimindo a procura interna. $\mathrm{O}$ que se tem que fazer é o contrário.

As ciências sociais estão hoje a produzir muitos argumentos que mostram, por exemplo, que a privatização da previdência é um desastre. Está provado por economistas de várias correntes. Vai encher os bolsos do capital financeiro, porque são estes que vão gerir o sistema de capitalização e de privatização das pensões, mas não é bom para as classes populares. A análise foi feita já cabalmente por exemplo no Chile, e o vosso ministro Paulo Guedes foi o homem que interveio nesse processo e deve conhecer muito bem as consequências desse sistema, mas, como é um banqueiro, naturalmente serve aos interesses do banco e não aos interesses do país - e é por isso que se pretende a privatização. De tal maneira é grave como chegou a ser mencionado no congresso por um dos ministros que os cortes nas universidades eram dependentes da privatização da previdência. Ou seja, o grande objetivo desse governo a nível econômico é criar um grande bolo de capital-dinheiro, não capital produtivo, para o capital financeiro. Essa é a mãe de todas as reformas. É por isso que se luta no Brasil nesse momento. Portanto, as ciências sociais criam argumentos que põem em causa muito daquilo que é hoje o discurso do capital dominante. Por outro lado, elas, naturalmente, vão contra o apagamento da memória. 
Se tem hoje, já no Brasil, uma crescente produção científica de ciências sociais produzida por cientistas negros e indígenas e também brancos e mestiços, ou pardos, como se diz no Brasil, com pesquisas que têm vindo a contribuir para descolonizar a história no Brasil, para dar outra perspectiva, outro conhecimento à história do Brasil. Por conseguinte, uma luta ativa mostrando o que foi o colonialismo, o que foi a escravatura. Tem o Jessé Souza, com sua "elite do atraso", e tantos outros livros que têm sido publicados que mostram efetivamente como há muito a se descolonizar, há muito o que se fazer para se descolonizar a própria educação brasileira e a universidade. Portanto, na universidade as ciências sociais têm esse papel de ir lutando contra o apagamento da memória. É nessa medida que elas servem à democratização. Porque é o apagamento da memória que impede as classes populares, que foram vítimas de racismo, e continuam a ser vítimas do racismo, que se transformem em atores políticos e em cidadãos ativos. Nós assistimos no Brasil à emergência de mais movimentos sociais de matriz africana e indígena com maior consciência social e com maior conhecimento social. Assim, é um enriquecendo da história do Brasil, uma ampliação da paisagem das ciências sociais e humanas brasileiras, que não é agora apenas um monopólio de uma pequena minoria de antropólogos, que estudavam os negros ou os indígenas. É uma pujante comunidade científica, sobretudo negra, que está a rever a história do Brasil. E tudo isso incomoda quem não quer ampliar a democracia. Quer dizer, é a velha divisão que a gente conhece no Brasil entre a casa-grande e a senzala. A senzala estava a educar-se e, ao educar-se, estava a querer entrar na casa-grande, que está a reagir de maneira brutal. Isso tem forte componente das ciências sociais e humanas. A casa-grande está apenas a tentar fechar as portas, mas, como elas são frágeis, o melhor é tentar fragilizar quem tenta forçá-las. Fragilizar essas classes que estavam a aumentar o seu capital educativo para poderem ter voz mais ativa na sociedade brasileira e ampliar, naturalmente, o espectro das alternativas políticas.

Professor, a sua experiência enquanto investigador das ciências sociais no Brasil acabou por forjar a sua própria ideia de epistemologia do saber, dos diferentes saberes que não são considerados em diferentes esferas, seja na política, seja na academia. Como a UPMS exemplifica uma tentativa de chegar a esses outros saberes e que lugar o pensamento de Paulo Freire, pensador tão atacado ultimamente no Brasil, ocupa nessa proposta?

Ainda bem que me faz essa pergunta, porque essa é uma forte dimensão da própria democratização do país e do mundo, no meu entender, que se dá por via da educação. É que, para a educação ser democratizadora, ela própria tem de ser democratizada. Temos de formar os formadores. Paulo Paulo Freire sempre foi uma grande referência para mim e é uma grande referência do que eu designo como epistemologias do Sul (Santos, 2016). Elas são a tentativa de podermos aprofundar as lutas sociais por meio do fortalecimento dos conhecimentos que elas produzem no mundo de hoje, que é altamente interdependente e onde há um padrão de atividade política e de conhecimento muito mais renovado do que no tempo das classes populares com quem trabalhou Paulo Freire. Ou seja, a educação tem de ser ela própria democratizada e em grande medida descolonizada. Por quê? Porque, 
mesmo quando ela procura abrir-se às classes populares, fala por uma perspectiva elitista. Isto é, com um conhecimento único, com um conhecimento rigoroso, que é o conhecimento científico, que durante séculos foi feito e produzido por homens e não por mulheres, por brancos e não negros nem indígenas, e dos países dominantes. Ainda hoje se vê que as citações dos livros científicos são fundamentalmente de autores do chamado norte global. Portanto, dei-me conta de que para fortalecer as lutas sociais era preciso criar outro sistema de justiça cognitiva. Isto é, para termos justiça social, precisamos ter justiça cognitiva. O que isso quer dizer? Precisamos de justiça entre os saberes.

As comunidades com que eu trabalhei desde os meus verdes anos de doutorando, vivendo numa favela do Rio de Janeiro, na favela do Jacarezinho, me ensinaram a sabedoria da população que vivia ali. Gente com quem eu convivi durante muitos meses e que me ensinou muitas coisas sobre o sentido de vida, sobre o que é justiça social, como é que se devia organizar o Brasil. Lembre-se de que eu fiz isso num período de ditadura no Brasil ainda. A partir daí, toda a minha trajetória foi no sentido de começar a valorizar o conhecimento não científico. A ciência social é fundamental para a nossa sociedade. Eu sou um cientista social, de maneira nenhuma tenho uma atitude anticiência. Agora o que eu digo é o seguinte: a ciência não é o único conhecimento válido, há outros conhecimentos válidos que têm de ser validados por seus próprios méritos. Ou seja, se eu quero ir à lua, eu preciso do conhecimento científico. Se eu quero conhecer a biodiversidade da Amazônia, eu tenho de conhecer o conhecimento dos indígenas e das populações ribeirinhas. São eles que conhecem a biodiversidade da Amazônia. Temos diferentes objetivos, temos diferentes conhecimentos. A grande parte da população mundial não vive com o conhecimento científico. Os camponeses no Brasil, a agricultura familiar, que continua a alimentar os brasileiros, continuam a ser uma cultura em que o saber popular, o saber vernacular é muito forte.

Os movimentos sociais, e nós vimos isso desde o Fórum Social Mundial de 2001, em que o Brasil teve papel protagônico, mostraram também que os movimentos organizados produziam conhecimento. Esse conhecimento não entrava na universidade. Assim, em 2003, propus ao Fórum Social Mundial a criação de uma UPMS, que basicamente tinha dois objetivos: por um lado, eliminar de alguma maneira a distância entre o conhecimento científico e o conhecimento popular. Os cientistas sociais e os cientistas em geral, na sua redoma de vidro, mesmo quando estão solidários com os pobres e com as classes populares, sempre se pensam como detentores do saber e que não há saber para além e fora da universidade, para além e fora da ciência. Portanto, era importante colocar em contato o conhecimento científico e o conhecimento popular. Por outro lado, o segundo objetivo era diminuir ou atenuar os preconceitos entre os diferentes conhecimentos populares, entre os saberes do movimento operário e os saberes dos movimentos de mulheres, entre o conhecimento dos movimentos indígenas e os do Movimento dos Trabalhadores Rurais Sem Terra (MST) e da reforma agrária - concepções diferentes da terra, concepções diferentes de território, concepções diferentes de dignidade e, consequentemente, muito preconceito e muita distância entre os próprios movimentos sociais. Para fortalecer os movimentos sociais, era preciso que se entendessem melhor 
e que se conhecessem melhor. Daí surgiram as oficinas da UPMS, que temos vindo a realizar por todo o mundo, em que, por dois dias, se juntam cerca de 40,50 pessoas, um terço acadêmicos, dois terços ativistas ou líderes de movimentos sociais, sempre movimentos sociais diferentes, nunca um só movimento, mas vários, para discutirem temas de interesse comum e propostas para os próprios movimentos. São eles que estabelecem uma agenda e fazem uma discussão na qual os acadêmicos não podem dar aulas, porque ninguém pode falar mais do que uns poucos minutos, mas onde se criam rodas de conversa dos vários conhecimentos que circulam.

Há aqui a influência óbvia de Paulo Freire, que tenho sempre salientado, mas traduzida para as novas exigências do mundo, onde também há muitos movimentos sociais que já têm seus intelectuais orgânicos. Têm os seus acadêmicos, gente com formação universitária, que mistura muitas vezes o conhecimento popular com o conhecimento universitário. Portanto, a UPMS tem vindo a tornar-se um instrumento daquilo que eu chamo de ecologia dos saberes, isto é, de articulação entre diferentes saberes, que por vezes obriga a ter uma tradução intercultural. Pensamos que isso contribui para aumentar a democracia. Como digo: aumenta a democratização do conhecimento, aumenta também a própria democracia. É uma proposta de paz, não de guerra, uma proposta de entendimento, de compreensão e de argumentação, não uma proposta de ódio, de liquidação de inimigos. É uma proposta em que se discutem argumentos diferentes de boa-fé e onde muitas vezes nas lutas se articulam diferentes conhecimentos.

Para dar um exemplo, eu estou bastante envolvido num movimento brasileiro contra os agrotóxicos, que envenenam a população, não só os consumidores, mas os próprios produtores e as suas comunidades, pelo fato de muitas vezes usarem produtos internacionalmente proibidos, ou por abusarem do seu uso sem o mínimo respeito pelas leis ambientais, que aliás existem no Brasil. É um movimento forte hoje no Brasil que combina perfeitamente o conhecimento científico de médicos, químicos, biólogos, engenheiros que estão conosco e o conhecimento dos movimentos dos camponeses, de indígenas, que em suas comunidades conhecem muito bem as consequências diretas do envenenamento a que estão sujeitos, pela pulverização em áreas ou desmatamento sem regras em seus territórios. Portanto, há aqui uma articulação de saberes. É nisso que essa democratização dos saberes, em meu entender, vai contribuir para a democratização da educação. Nós temos feito convênios da UPMS com várias universidades do mundo, não apenas no Brasil, mas também no México, na Costa Rica, com os departamentos de extensão, para poder articular o conhecimento universitário e a universidade com esse conhecimento popular. É nisso que eu penso que pode contribuir para a maior democratização da educação e também para capacitá-la a ser democratizadora e descolonizadora numa sociedade tão desigual como é o Brasil e, infelizmente, o mundo no seu todo.

Qual é a importância do encontro de professores, pesquisadores, estudantes de pós-graduação e professores da educação básica nesse momento na 39a Reunião Nacional da ANPEd, em que o senhor será o conferencista de abertura?

É de importância crucial. Talvez nunca tenha sido tão importante como dessa vez, sobretudo em período mais recente, porque, antes de mais nada, é a importância 
de se defender a democracia. Eu penso que nesse momento defender a educação, a pesquisa e a escola pública é defender a democracia brasileira. Portanto, é defender um futuro democrático para as novas gerações. É tão básico quanto isso. Também estaremos nesse encontro não só em defesa da democracia, mas também como uma promoção ativa do enriquecimento e do aprofundamento da democracia e do autoconhecimento do Brasil, por meio dos seus educadores e, por conseguinte, mediante uma rede geral da educação e da pesquisa. É esse o objetivo.

\section{REFERÊNCIA}

SANTOS, B. de S. Para uma nova visão da Europa: aprender com o Sul. Sociologias, Porto Alegre, ano 18, n. 43, p. 24-56, set./dez. 2016. Disponível em: http://dx.doi. org/10.1590/15174522-018004302. Acesso em: 1 out. 2019.

\section{SOBRE OS AUTORES}

Boaventura de Sousa Santos é doutor em sociologia do direito pela Universidade de Yale (Estados Unidos). Professor da Universidade de Coimbra (Portugal).

E-mail: bsantos@ces.uc.pt

João Marcos Veiga de Oliveira é mestre em história pela Universidade Federal de Minas Gerais (UFMG). Assessor de comunicação da Associação Nacional de Pós-Graduação e Pesquisa em Educação (ANPEd). E-mail: joaomarcosveiga@gmail.com

Maria Luiza Süssekind é doutora em educação pela Universidade do Estado do Rio de Janeiro (UERJ). Professora da Universidade Federal do Estado do Rio de Janeiro (UNIRIO).

E-mail:1uli551@hotmail.com

Recebido em 27 de maio de 2019

Aprovado em 30 de agosto de 2019 